\title{
- Alinhamento entre a Estratégia e as Competências Organizacionais: o caso de uma empresa nacional líder do segmento de revestimentos cerâmicos
}

\author{
Marinaldo de Brida ${ }^{1}$ \\ Jair Nascimento Santos ${ }^{2}$
}

\section{Resumo}

O principal objetivo deste estudo é apresentar e discutir como acontece o alinhamento entre as estratégias empresariais e as competências organizacionais. A partir do referencial teórico e da experiência de uma empresa estudada, este trabalho identifica quais são as características da empresa e como deve ser um ambiente organizacional para promover este alinhamento. Como uma empresa deve proceder e quais ferramentas podem ser utilizadas para possibilitar a participação dos funcionários de todos os níveis e áreas, desde o planejamento até a execução do seu plano estratégico e do programa de gestão por competências. Apresenta também, a importância do desenvolvimento das competências ligadas a estratégia, denominadas competências essenciais, que resultam em um desenvolvimento organizacional. Este desenvolvimento organizacional ocorre com o treinamento dos funcionários e com o crescimento de suas respectivas competências individuais, promovendo a ligação entre as estratégias empresariais e as competências organizacionais por meio da aprendizagem organizacional e individual.

Palavras-chave: Planejamento estratégico. Administração estratégica. Competências organizacionais. Gestão de pessoas. Competências essenciais. Competências individuais.

1 Mestre em Administração pela Universidade Salvador - UNIFACS. Pesquisador do NEOTEG, Salvador - BA, Brasil. End.: Rua 262, n.99, Meia Praia, Itapema-SC. Cep: 88220-000 - Brasil. E-mail: marinaldodebrida@hotmail.com.

2 Doutor em Administração pela Universidade Federal de Minas Gerais - UFMG. Professor da Universidade Salvador - UNIFACS e da Universidade Estadual de Feira de Santana - UEFS. End.: Av. Universitária, s/n, Campus Universitário, Feira de Santana - BA. CEP: 44031-460 - Brasil. E-mail: jair.santos@unifacs.br.

Artigo recebido em: 1\%02/2011. Aceito em: 04/05/2011. Membro do Corpo Editorial Científico responsável pelo processo editorial: Martinho Isnard Ribeiro de Almeida. 


\section{Introdução}

Muitos autores defendem que, para que mecanismos de gestão resultem em vantagem competitiva, a gestão estratégica da empresa deve estar alinhada a um sistema de gestão de pessoas por competência. Dessa forma, o conceito de competência assumiu relevância por estabelecer relações entre a estratégia, as funções críticas, as competências essenciais da organização e as competências individuais. Esse alinhamento entre a estratégia e as competências torna a empresa mais homogênea em seus objetivos presentes e futuros, pois o funcionário, desde o nível mais operacional, estará ciente das metas de seu cargo e terá uma visão mais ampliada do negócio da organização e da importância de sua atividade para que a empresa obtenha sucesso (ZARIFIAN, 2001).

Nesse processo desenvolve-se uma visão mais objetiva do potencial dos funcionários, que são indispensáveis para as organizações com seus conhecimentos, habilidades e atitudes. As pessoas deixam de ser apenas recursos e passam a ser vistas como seres vivos, com sentimentos, inteligência e aspirações, $e$, cada vez mais, se voltam para o desenvolvimento de suas competências. Um sistema de gestão de pessoas deve, portanto, ter como objetivo desenvolver e estimular as competências individuais necessárias para que as estratégias organizacionais se viabilizem (COSTA, 2003).

Considerando-se a importância deste tema para as organizações, este trabalho teve como questão principal responder como acontece o alinhamento entre a estratégia e as competências organizacionais. Para isso, foi importante entender como conseguir o envolvimento e participação dos funcionários na gestão estratégica, $e$ também entender se a visão deles sobre o programa de gestão por competências influencia neste alinhamento. Da mesma forma, foi importante entender como ocorre o desenvolvimento das competências individuais e como isto contribui neste processo. Foram analisadas quais são as características de uma empresa e o que ela deve fazer para obter um ambiente propício para o alinhamento entre estratégia e competências organizacionais e a importância da comunicação e quais as ferramentas que podem ser utilizadas para promover a participação dos funcionários na gestão da estratégia.

O tema escolhido para este estudo foi analisado a partir das suas abordagens atuais confrontado com a experiência de uma empresa do ramo cerâmico constituída de dois polos produtivos: a matriz no Sul do Brasil, estado de Santa Catarina e um polo no nordeste situado na Bahia. Essa empresa realizou entre 
2006/2008, como parte de seu planejamento estratégico, a implantação de um sistema de gestão por competências.

A seguir serão apresentados os conceitos teóricos que visam fundamentar o modelo de análise para o caso estudado, a metodologia utilizada e as considerações finais do trabalho.

\section{Estratégia: do planejamento à administração estratégica}

Existem muitos conceitos sobre estratégia na literatura em que o termo aparece associado a um conjunto de regras estabelecidas, que funcionam como diretrizes orientadoras das decisões e comportamentos para todas as camadas da empresa e conduzem para a realização de seus objetivos. Andrews (1971), por exemplo, define a estratégia corporativa como o modelo de decisão da empresa em que estão definidos os objetivos, metas, normas e planos, e que delimita as fronteiras do negócio e da atuação da organização.

Da mesma forma, Certo e Peter (1993) definem planejamento estratégico como um processo contínuo (uma série de etapas) e interativo que visa manter uma organização como um conjunto apropriadamente integrado ao seu ambiente. Estes autores colocam ainda que no início da concepção da gestão estratégica é necessária sua estruturação formal, como um plano, e definição de etapas que incluem: a análise do ambiente, a missão, a visão, o objetivo organizacional, a formulação e implementação das estratégias e a definição de indicadores de controle. Todas estas etapas devem ser discutidas e entendidas pelo maior número possível de pessoas na empresa. É muito importante o envolvimento de toda a organização e não somente da alta gerência, porque sem o comprometimento de todos, dificilmente haverá sucesso.

Mas, para Mintzberg e Quinn (2001), a estratégia é mais que um conjunto de regras formais. É necessário que os indivíduos possam ser agentes, em conjunto, do processo de evolução do objetivo estratégico, e é recomendável que as estratégias se desenvolvam de forma gradual através de ações e experiências da organização.

Por isso que, segundo Ferreira, Reis e Pereira (1997), a partir dos anos de 1980 com o intuito de conservar os benefícios propiciados pelo planejamento estratégico, porém, combatendo suas imperfeições, surge a administração es- 
tratégica, com mais amplitude, profundidade e complexidade. A administração estratégica tem como objetivo desenvolver em todos os níveis hierárquicos os valores da corporação, sua capacidade gerencial, suas responsabilidades como organização inserida na sociedade e os seus sistemas administrativos, que interligam o processo de tomada de decisão estratégica, tática e operacional (FISCHMANN, 1987).

Mesmo reforçando a diferença entre planejamento e a administração estratégica, Costa (2003) alerta para a importância destes para o sucesso do processo. Para a autora, na formulação das estratégias, dois aspetos devem ser considerados: o planejamento, com as respectivas estratégias deliberadas, e a administração estratégica, com as emergentes, que dependem do desenvolvimento das competências individuais. Enquanto o planejamento estratégico é visto normalmente como um plano formal, restrito a estratégias comerciais e financeiras, a administração estratégica é entendida como a antítese dos arquétipos organizacionais centralizados e burocráticos voltados para somente uma parte da organização. Mas, não são modelos excludentes, pelo contrário, observa-se na literatura atual a coexistência desses conceitos entendida como um processo interativo.

\section{Competências: organizacionais, individuais e essenciais}

Quanto à sua aplicação, o conceito de competência pode estar vinculado ao plano organizacional (competências organizacionais e essenciais), das pessoas (competências individuais) e dos países (sistemas educacionais e formação de competências).

Na definição apresentada por Parry (1996), o conceito de competência individual é associado ao treinamento e ao desenvolvimento. Ele define competência individual como um agrupamento de conhecimentos, habilidades $e$ atitudes relacionadas que afetam grande parte do trabalho de uma pessoa (um papel ou uma responsabilidade), e que se correlaciona com sua performance no trabalho, podendo ser medida em comparação com os padrões estabelecidos e ser passível de melhoras por meio de treinamento e desenvolvimento.

Já Dutra (2001) relaciona a ideia de competência à noção de entrega, ou seja, à capacidade do indivíduo entregar-se à empresa. $\mathrm{O}$ fato de um indivíduo 
possuir um determinado conjunto de conhecimentos, habilidades e atitudes não garante à empresa a apropriação desses elementos; daí a necessidade da entrega por parte do indivíduo. Zarifian (2001) também concorda com o exposto quando define a competência individual como "[...] o 'tomar iniciativa' e o 'assumir responsabilidade' do indivíduo diante das situações profissionais com as quais depara." (ZARIFIAN, 2001, p.44). Por tomar iniciativa entende-se fazer escolhas, selecionar estratégias e tomar atitudes a partir do conhecimento acumulado e da iniciativa apresentada em situações de imprevisibilidade. Por assumir responsabilidades entende-se que sejam atendidos objetivos ligados a prazos, à confiabilidade, à satisfação de clientes e ao conhecimento. Neste momento no conceito de competência, o indivíduo assume poder de decisão e de participação nas questões estratégicas da empresa, devendo ser responsável e reconhecido por isso. Para assumir essa definição, torna-se necessário desenvolver um ambiente que incentive a aprendizagem organizacional, essencial no desenvolvimento da competência, sendo preciso conceituá-la também como um entendimento prático de situações que se apoiam em conhecimentos adquiridos e os transforma na medida em que aumenta a diversidade das situações (ZARIFIAN, 2001).

A noção de competência no nível organizacional ganhou destaque na pesquisa em administração na década de 90 quando Prahalad e Hamel publicam The Core Competence of the Corporation, livro no qual os autores declaram que empresas de sucesso apoiam-se em recursos especiais, que eles chamam de competências essenciais.

Ao discorrer sobre definições de competências organizacionais, Mills et al. (2002) afirmam ser uma forma de descrever o quão bem uma empresa desempenha suas atividades de sucesso, superando seus concorrentes em um fator competitivo que o cliente valorize. Que devem ser entendidas como variáveis, como algo que as empresas realizam em determinado nível e não como atributos, algo que as empresas tenham ou não. Para eles a competência é construída a partir de recursos articulados e coordenados. Um único recurso como uma máquina, um indivíduo ou mesmo uma pequena equipe, não pode constituir competência.

Nisembaum (2000) destaca dentre as competências organizacionais, as competências básicas e as essenciais. As competências básicas são pré-requisitos fundamentais que a empresa precisa ter para desenvolver uma administração eficaz, e representam as condições necessárias, porém não suficientes, para que a 
empresa alcance liderança e diferencial no mercado em que atua. As competências essenciais oferecem reais benefícios ao consumidor, são difíceis de imitar e proveem acesso a uma ampla variedade de mercados (PRAHALAD; HAMEL, 1990).

Fleury e Fleury (2004) deixam ainda mais claro o que foi apresentado, ao explicar a dinâmica entre os diversos níveis de competência que se formam na organização. Segundo os autores, em um nível mais geral, há as competências organizacionais que se formam nas unidades e funções; destas, algumas são consideradas competências essenciais e são básicas durante a elaboração da estratégia competitiva. As competências essenciais produzem atributos que constituem as competências distintivas percebidas pelos clientes. Ainda ressaltam que as competências são formadas a partir da combinação de recursos da organização e de competências individuais e, ao definir sua estratégia competitiva, a empresa identifica as competências essenciais ao negócio e as competências necessárias a cada função - as competências organizacionais. Assim, a organização possui diversas competências organizacionais localizadas em diversas áreas; destas, apenas algumas são as competências essenciais, aquelas que a diferenciam e que lhe garantem uma vantagem competitiva sustentável perante as demais organizações. Tal competitividade vai depender, a longo prazo, da administração do processo de aprendizagem organizacional que vai reforçar e promover as competências organizacionais; e vai dar foco e reposicionar as estratégias competitivas.

\section{Alinhamento da Estratégia e as Competências da Organização}

Apesar da importância do alinhamento estratégico ser abordada e difundida por muitos autores, Currie e Darby (1995) apontam que a falta de clareza na definição das competências e a falta de ligação com a estratégia da corporação, ainda destacam-se como os principais problemas enfrentados na implementação da gestão por competências. Essa falta de ligação com a estratégia corporativa é crítica, pois o ponto-chave da gestão de pessoas por competências é que todo o processo deve estar alinhado à definição das estratégias de negócio e das competências essenciais da organização (FLEURY; FLEURY, 2001).

Para Kaplan e Norton (2000), o bom desempenho de uma empresa é alcançado quando a estratégia é comunicada de forma coerente, clara e de 
fácil entendimento em todos os níveis da organização, tornando importante o processo de comunicação. A estratégia deve estar conectada e integrada dentro de toda a organização criando sinergia, ou seja, ela deve ser uma tarefa de todos, em um processo contínuo. E a mudança deve ser realizada por meio da liderança executiva.

De acordo Brandão e Guimarães (2001), o alinhamento acontece quando a gestão de competências envolve os diversos níveis da organização desde o corporativo até o individual, passando pelo divisional e grupal, forma-se assim um processo circular. Dessa forma, o importante é que a gestão de competências esteja em perfeita sintonia com a estratégia (missão, visão de futuro e objetivos).

Costa (2003) aborda a questão da aprendizagem como fator condicionante para as pessoas se constituírem num fator de vantagem competitiva em uma organização, e para demonstrar o alinhamento com a estratégia. Segundo a autora, o nexo entre estratégias empresariais e as competências individuais é a aprendizagem organizacional e individual. Enquanto a aprendizagem organizacional se dá, entre outras fontes, a partir de novas tecnologias, a individual se dá por meio de educação e treinamento.

Fleury e Fleury (2001) apresentam um modelo para alinhar as estratégias às competências. A lógica para o alinhamento consiste na análise das necessidades e do negócio da empresa. A partir da definição de competência individual, os autores constroem uma ponte que permite articulá-la à competência organizacional. Essa ponte passa pelo conceito de estratégias competitivas, que podem ser classificadas em excelência operacional, inovação em produtos e orientação para serviços, conforme Quadro 1.

\begin{tabular}{|c|c|c|c|}
\hline \multirow{2}{*}{$\begin{array}{c}\text { Estratégia } \\
\text { Empresarial }\end{array}$} & \multicolumn{3}{|c|}{ Competências Essenciais } \\
\cline { 2 - 4 } & Operações & Produto & Marketing \\
\hline $\begin{array}{c}\text { Excelência } \\
\text { operacional }\end{array}$ & $\begin{array}{c}\text { Manufatura } \\
\text { classe mundial }\end{array}$ & $\begin{array}{c}\text { Inovações } \\
\text { incrementais }\end{array}$ & $\begin{array}{c}\text { Marketing de produto para } \\
\text { mercados de massa }\end{array}$ \\
\hline $\begin{array}{c}\text { Inovação } \\
\text { em produto }\end{array}$ & $\begin{array}{c}\text { Scale up e fabri- } \\
\text { cação primária }\end{array}$ & $\begin{array}{c}\text { Inovações } \\
\text { radicais }\end{array}$ & $\begin{array}{c}\text { Marketing seletivo para mercados/ } \\
\text { clientes receptivos a inovação }\end{array}$ \\
\hline $\begin{array}{c}\text { Orientada } \\
\text { para serviços }\end{array}$ & $\begin{array}{c}\text { Manufatura } \\
\text { ágil, flexível }\end{array}$ & $\begin{array}{c}\text { Desenvolvimen- } \\
\text { to de soluções e } \\
\text { sistemas específicos }\end{array}$ & $\begin{array}{c}\text { Marketing voltado a clientes } \\
\text { específicos (customização) }\end{array}$ \\
\hline
\end{tabular}

Quadro 1: Tipos de estratégia e competências organizacionais Fonte: Fleury e Fleury (2001, p. 74) 
Segundo Fleury e Fleury (2001), uma empresa tem que explorar e desenvolver suas competências essenciais de maneira consistente com as estratégias empresariais definidas. Não é interessante para uma empresa assumir que é igualmente competente em todas as três funções, seja ela a excelência operacional, a inovação em produtos ou orientação para clientes.

A excelência operacional, de acordo com os autores, caracteriza empresas que em geral, oferecem produtos padronizados, do tipo commodity, e que buscam competir com base no custo. É nessa função que reside a competência essencial, a que deve ser priorizada para que a empresa tenha sucesso. A inovação em produtos caracteriza empresas que procuram oferecer a seus clientes produtos de vanguarda e inovadores e a orientação para serviços caracteriza empresas voltadas a atender clientes específicos, especializando-se em satisfazer $e$ até antecipar as necessidades desses clientes em função de sua proximidade com eles (FLEURY; FLEURY, 2001).

Em suas pesquisas, Fisher (1998) observou como é a prática das empresas mais avançadas no processo de alinhamento (consideradas modelos para as demais). Elas procuram captar pessoas com nível educacional mais elevado e tem os programas de trainees como ferramenta para atrair novos talentos, possibilitando renovação futura do quadro. São empresas que buscam pessoas preocupadas com o autodesenvolvimento. Elas utilizam novas formas de remuneração como participação nos resultados, remuneração variável e existe ainda, a ligação da remuneração com instrumentos de avaliação de performance e de desempenho tomando como base as competências.

Da mesma forma Fleury e Fleury (2001) têm observado em seus trabalhos de consultoria mudanças significativas nas práticas de gestão das empresas que incorporam o conceito de competência. Novas técnicas e ferramentas estão sendo utilizadas nos processos de recrutamento e seleção, com o objetivo de identificar pessoas com potencial de crescimento e com pensamento estratégico. Novos contornos são assumidos nos processos de desenvolvimento e treinamento, criando-se em algumas empresas o conceito de universidade corporativa. O ponto-chave desse conceito é que todo processo de desenvolvimento deve estar alinhado à definição de estratégias e competências essenciais da organização. Segundo os autores é possível identificar algumas tendências gerais de mudanças de estrutura e sistema de gestão nas empresas consideradas mais avançadas no alinhamento entre estratégia e competências. A partir de pesquisas realizadas com empresas brasileiras, eles apresentam os aspectos 
mais relevantes e os indicadores qualitativos e quantitativos que possibilitem esta visão:

a) A posição da primeira pessoa responsável pelo $\mathrm{RH}$ na estrutura hierárquica da empresa denota a preocupação da empresa em alinhar a gestão de pessoas e de competências às estratégias do negócio. Quanto mais alta a posição, maior será a probabilidade das pessoas serem consideradas recursos estratégicos e do responsável por $\mathrm{RH}$ ter voz ativa nas decisões.

b) É importante ter as políticas de gestão documentadas e atualizadas, pois a revisão recente das políticas de $\mathrm{RH}$ indica que a gestão de pessoas é valorizada na empresa.

c) São adotadas políticas para atrair, reter e desenvolver as pessoas necessárias para o sucesso das estratégias. $\mathrm{O}$ uso de políticas de remuneração variável ou participação nos lucros para todas as funções é um indicador de modernidade de gestão, pois todos os empregados devem participar dos resultados do negócio.

d) A adoção de estratégias para a participação dos empregados, como os tradicionais programas de sugestão, indica a disposição por parte da empresa em desenvolver propostas de melhoria contínua e aprendizagem entre os funcionários.

e) A capacidade de a empresa reter seus empregados é mensurada pelo índice de rotatividade. Nas empresas estudadas o nível de rotatividade foi de $5,7 \%$ ao ano.

f) O nível educacional dos funcionários em suas várias posições e funções é um primeiro indicador da base de conhecimentos formais, necessária para a construção das competências organizacionais.

g) Investimento em treinamento e desenvolvimento dos funcionários, para o desenvolvimento de competências. As empresas pesquisadas apresentaram uma média de 37 horas de treinamento por funcionário por ano. 
Ainda segundo Costa (2003), em relação à ocorrência do alinhamento entre estratégias e competências, pode-se obter dados que levem a essa afirmação. Ao considerar que as competências foram desdobradas dos objetivos e estratégias, o resultado geral da avaliação de desempenho servirá para verificar o grau de alinhamento. Pode-se deduzir que há uma forte relação entre as competências e as estratégias se, o resultado final apontar que a maioria dos empregados atende as competências individuais requeridas. Da mesma forma, sendo os executivos os verdadeiros agentes da mudança, os resultados das avaliações das competências dos gestores são uma fonte importante para a verificação do alinhamento, assim como, a percepção deles em relação ao sistema de gestão de pessoas por competências. Como a comunicação insuficiente também leva a uma falta de participação e envolvimento das pessoas, deve-se verificar como o processo é entendido e como é a aceitação das pessoas, principalmente os gestores. Os objetivos e as estratégias devem ser negociados, validados e desdobrados em todos os níveis da empresa através da interação da liderança e demais empregados. E para atingir os resultados esperados as competências essenciais devem ser selecionadas e inventariadas a partir do desdobramento das estratégias de negócio, pois elas serão mais eficazes à medida que chegarem ao nível do indivíduo.

\section{Metodologia de Pesquisa}

A metodologia de desenvolvimento do presente trabalho foi um estudo de campo, utilizando a abordagem de pesquisa qualitativa, com as entrevistas abertas, e a quantitativa, com a aplicação de questionário. Esta pesquisa também foi classificada como sendo descritiva quanto aos fins, porque procurou descrever as ações implementadas para se obter o alinhamento entre estratégias e competências. Quantos aos meios, ela é classificada como documental e estudo de caso. Esta pesquisa é considerada documental por fazer uso de documentos internos contendo informações acerca do planejamento estratégico e do sistema de gestão por competências, que vieram a complementar as informações obtidas nas entrevistas. E estudo de caso porque foi analisada uma única empresa. Os elementos do estudo foram, portanto, os funcionários da Eliane Revestimentos Cerâmicos, do Polo Sul e do Polo Nordeste. A Eliane Revestimentos Cerâmicos Ltda. é uma empresa com a matriz sediada em Co- 
cal do Sul-SC e um polo produtivo em Camaçari, Bahia. Essa empresa revisa anualmente seu planejamento estratégico e implementou, no ano de 2006, um programa de gestão de pessoas baseado no modelo de competências.

Foram definidos como parte integrante da pesquisa, os funcionários de todos os níveis e áreas, já que a literatura estudada apresenta como uma premissa básica para o alinhamento entre estratégia e competências, que todos os funcionários da empresa sejam envolvidos no sistema de gestão. A coleta de dados foi realizada mediante o uso de procedimentos definidos: aplicação de questionários, análise de documentos e registros organizacionais e realização de entrevistas semiestruturadas com os funcionários que compõem a equipe responsável pelo planejamento estratégico da empresa e pelo sistema de gestão de pessoas por competência.

O questionário aplicado foi elaborado especificamente para esta pesquisa e era composto por 26 frases para o respondente decidir sobre seu nível de concordância no formato de escala Likert, variando de 1 a 5 (de discordo totalmente a concordo totalmente). No questionário foram listadas as competências organizacionais definidas pela empresa, de modo a facilitar o entendimento $e$ as respostas.

A empresa contava em 2009 com 2.510 funcionários, sendo $70 \%$ do nível operacional. Foram enviados questionários a 334 funcionários de todos os níveis e áreas da empresa, que foram sorteados de forma aleatória a partir do número de sua matrícula na empresa.

Outra forma de obter as informações sobre a empresa foram as entrevistas. Foram realizadas entrevistas semi-estruturadas com o superintendente de planejamento estratégico (SPE) e a gerente de recursos humanos (GRH). O objetivo destas entrevistas foi obter informações sobre o ambiente da empresa e entender como funcionam as áreas de planejamento estratégico e recursos humanos.

Também com objetivo de complementar as informações obtidas na entrevista sobre a empresa e o funcionamento de seu sistema de gestão, foi realizada análise de documentos e registros organizacionais. A pesquisa documental realizou-se na própria empresa em horário agendado previamente. Os documentos internos pesquisados foram: intranet (www.elianet.com.br), relatório social 2008 e organograma da empresa. 
Os dados obtidos da aplicação do questionário foram codificados, tabulados e, depois, foi realizado o tratamento estatístico por meio do software Statistical Package for the Social Sciences (SPSS).

Para realizar a análise dos resultados do questionário foi utilizada uma abordagem quantitativa para a escala tipo Likert e foi estabelecido o Ranking Médio (RM) para mensurar o grau de concordância dos funcionários em cada frase. Para o cálculo do ranking médio foi utilizado o método de análise sugerido por Malhotra (2001), que nada mais é do que uma média ponderada. Baseado no ranking médio da pontuação atribuída às respostas, foi analisada a concordância ou discordância das frases avaliadas. Ou seja, os valores menores que três são considerados como discordantes e, maiores que três, como concordantes, considerando a escala de cinco pontos. O valor exatamente três é equivalente aos casos em que os respondentes deixaram em branco, seria considerado "sem opinião", sendo o "ponto neutro".

Foi analisada também a frequência das respostas dos participantes e o respectivo percentual $(\%)$ de concordantes e discordantes de cada frase do questionário. $\mathrm{O}$ percentual de concordantes foi obtido somando-se os que responderam "concordo parcialmente" ou "concordo totalmente".

Em suma, este trabalho pode ser caracterizado como um estudo de caso descritivo, no qual sua pesquisa foi qualitativa e quantitativa.

\section{Resultados da Pesquisa}

\subsection{Levantamento Histórico-Estratégico e das Características da Empresa Estudada}

Em 1960, o empresário Maximiliano Gaidzinski fundou uma empresa de revestimentos cerâmicos no município de Cocal do Sul, na região sul do estado de Santa Catarina, próximo a Criciúma. Nascia então a Maximiliano Gaidzinski S/A - Indústria de Azulejos Eliane. Por meio de um sucessivo processo de aquisições realizado durante cinco décadas essa empresa alcançou a liderança nacional na fabricação e exportação de revestimentos cerâmicos. 
Em 2005, a empresa teve seu recorde de volume na exportação equivalente a $46 \%$ das vendas. Com a valorização do real frente ao dólar iniciada no ano de 2004, começaram os problemas pois, tratava-se de uma empresa que já exportava quase $50 \%$ de sua produção. A maioria das exportações era para a América do Norte. Os bons resultados obtidos até então eram justamente devidos à alta nas exportações e uma situação cambial favorável.

Segundo o entrevistado SPE (2010)

[...] como parte do planejamento estratégico da empresa, em 2005 foi elaborado um plano de negócios 2006-2010 para interromper um ciclo de forte redução de lucratividade motivado por diversos fatores, dentre os quais, a significativa desvalorização do dólar face ao real e incrementos de custos/ despesas superiores ao preço dos produtos.

Dentre as principais premissas do plano de negócios em execução estavam ações de concentração das atividades fabris nos polos industriais das regiões Sul e Nordeste. O Sul, nas cidades catarinenses de Cocal do Sul e Criciúma e o Nordeste localizado em Camaçari, BA. A planta de Minas Gerais e parte da planta do Espírito Santo foram transferidas para Bahia. E a planta do Paraná e alguns equipamentos do Espírito Santo, para Santa Catarina. Além disso, buscava o fortalecimento das ações mercadológicas no mercado doméstico, a concentração na atividade fim (core-business) e a desmobilização dos ativos ociosos.

O entrevistado GRH (2010) relatou que é importante destacar ainda, que "[...] mais do que investir em máquinas e produtos foram retomados os investimentos nas pessoas. Isto está expresso na implantação do programa de Gestão por Competências".

\subsection{Sistema de Gestão: estratégia e competências na empresa estudada}

De acordo com o entrevistado GRH, o sistema de gestão da empresa estudada tem na certificação ISO 9001, uma das suas bases de estruturação. A empresa tem suas políticas de $\mathrm{RH}$ documentadas e atualizadas, e a sua última revisão foi em maio de 2009. E o responsável pelo $\mathrm{RH}$ não está no nível 
de diretoria, o que seria mais interessante segundo a teoria, ele ocupa uma função gerencial, e responde hierarquicamente para a diretoria administrativa e financeira.

Os funcionários participam do processo estratégico através do programa de melhorias. Este programa mantido pela empresa completou 12 anos em 2009 e integra o Núcleo Catarinense de Círculos de Controle de Qualidade desde 1999. Os funcionários participantes se reúnem em Grupos de Estudos e Sugestões (GES) que elaboram projetos de melhorias e inovações nos processos, segurança e redução de desperdício. Os projetos têm como incentivo uma premiação para os membros dos grupos que se destacam mensalmente $e$ anualmente.

Segundo o entrevistado SPE (2010), “[...] a empresa tem no ano de 2005 um marco inicial de um processo formal de planejamento estratégico mais estruturado". Para auxiliar na elaboração do planejamento estratégico a empresa contratou uma consultoria externa, e para acompanhamento das estratégias definidas foram formados comitês: comitê de Gestão de Riscos, comitê de Produtos e Marketing e comitê de Recursos Humanos. O resultado do trabalho desses comitês é levado para a análise do Conselho Administrativo.

\subsection{Planejamento Estratégico da Empresa Estudada}

De acordo com as informações levantadas na entrevista de SPE, o planejamento estratégico propriamente dito foi realizado entre 2005 e 2006, com o objetivo de estabelecer ações para o período de 2006 a 2010. Foram vários consultores externos utilizados com o objetivo de trazer a metodologia, e não a definição da estratégia em si. Foram criados grupos com representantes de todas as áreas da empresa: conselheiros, diretores, superintendentes, gerentes, coordenadores, alguns supervisores e também representantes da área de recursos humanos. Foi montada uma sala chamada de "sala de guerra", local onde todas as pessoas ficaram liberadas para trazer ideias e sugestões. Os ambientes interno e externo à operação também foram analisados durante exercício de planejamento estratégico através da utilização da análise SWOT e foi adotada uma metodologia em que os objetivos estratégicos foram desdobrados em metas individuais com prazo e orçamento definidos.

O planejamento realizado elencou uma série de ações nas esferas industrial, comercial, financeira e de pessoal. 
Para o entrevistado SPE (2010), na

[...] esfera industrial uma das ações mais importantes foi o projeto de concentração fabril. Com relação à gestão de pessoas, entre as ações mais importantes está a implantação do programa de Gestão por Competências, e para isso foi contratada uma consultoria especializada na área para auxiliar no processo.

A missão, a visão e os valores foram definidos em 2005 pelo conselho Administrativo da empresa, que é formado por membros da família fundadora e por profissionais contratados. A empresa de consultoria auxiliou na definição e os conceitos foram amplamente divulgados na organização. Durante o ano de 2008, o entrevistado GRH (2010) salienta que

[...] foram realizados treinamentos com todos os funcionários do grupo, de todos os níveis, onde foram difundidos os temas como missão, visão, valores e também as competências organizacionais da empresa.

Com relação ao controle e à avaliação da estratégia na empresa estudada, SPE (2010), afirma que "[...] o acompanhamento acontece através de reuniões bimestrais para análise do Balanced Score Card (BSC) e é realizado com um grupo de oito pessoas onde está inserida a gerente de RH". A empresa dividiu seus indicadores nas quatro perspectivas: Financeira, Aprendizado e Crescimento, Processos de Internos e Operações com Clientes. Foi desenvolvida internamente e disponibilizada na intranet da empresa uma ferramenta chamada "Painel Estratégico", no qual pode-se acessar esses indicadores mediante uma liberação por senha. Cada nível tem acesso aos indicadores de sua área de atuação, cabendo à diretoria, ao conselho e aos superintendentes o acesso $e$ a análise dos indicadores globais. Como indicador da área de gestão de pessoas, o entrevistado GRH diz que a empresa utiliza a rotatividade. Sendo que nos últimos anos ela tem se mantido estável. 


\subsection{Gestão por Competências na Empresa Estudada}

Conforme informado pelo entrevistado GRH (2010), "[...] o projeto de gestão por competências na empresa estudada foi dividido em ciclos". No primeiro ciclo foi realizado o mapeamento das competências organizacionais e a sensibilização dos gestores da empresa e da área de $\mathrm{RH}$ para compreensão do modelo. Essas competências organizacionais que foram definidas durante este processo são as seguintes: foco em resultados, trabalho em equipe, visão estratégica, autonomia e decisão, comprometimento com gastos $e$ foco no cliente. No segundo ciclo, foram reunidas as altas gerências e as gerências intermediárias para realizar o desmembramento das competências organizacionais em atitudes observáveis, formando o relatório com as competências e respectivas atitudes descritas. Dessa forma, ocorreu a instrumentalização do $\mathrm{RH}$ para realizar a seleção de gestores segundo as competências organizacionais. Também ocorreu a disseminação das competências e incentivo ao exercício de atitudes alinhadas às competências, para através da comunicação obter a sensibilização e aderência dos funcionários.

No terceiro ciclo, que está atualmente em andamento, a empresa se prepara para a realização das avaliações de desempenho por competências. Por enquanto, avaliação de desempenho é utilizada apenas para as alterações salariais, para promoções e para os casos de baixo desempenho do funcionário.

No quarto e no último ciclo, está prevista a implementação de um sistema de remuneração por competência. A empresa adota atualmente, de maneira geral, um modelo tradicional baseado na estrutura de cargos. Mas, para a área comercial e para as funções de coordenadores e gerentes na área industrial, a empresa utiliza remuneração variável.

\subsection{Comunicação na Empresa Estudada}

De acordo com o entrevistado GRH, a empresa trabalha a comunicação interna utilizando várias ferramentas com o objetivo de fortalecer e padronizar a comunicação institucional, ganhar credibilidade, promover a transparência $e$ reforçar a conscientização e motivação para alcançar os objetivos institucionais e da comunidade interna.

Para isso, foi implantado, na empresa estudada em janeiro de 2007, a comissão de comunicação interna, batizada de "Canal Aberto. A Comissão faz 
uma análise profunda dos veículos de comunicação interna e de como eles se relacionam e se complementam.

\subsection{Desenvolvimento e Crescimento}

De acordo com o entrevistado GRH (2010), uma das políticas de recursos humanos da empresa é "[...] privilegiar o recrutamento e a seleção interna, identificando e aproveitando os talentos internos". Essa empresa não tem programa de trainees e nem qualquer outra ferramenta para atrair novos talentos. A empresa tem um colégio próprio, Colégio Maximiliano Gaidzinski (CMG), que utiliza como fornecedor de mão de obra técnica e estão estudando modificações na grade curricular do curso para acrescentar cadeiras de gestão de pessoas.

Dentre as várias características dessa empresa, pode-se ver no perfil dos 2.510 empregados um nível interessante de escolaridade, mesmo nas funções operacionais. O ensino médio completo (segundo grau) atualmente é o mínimo exigido para operador industrial. A empresa oferece bolsa de estudos de $70 \%$ para o ensino médio e $50 \%$ para o ensino técnico. Os dados fornecidos pela empresa mostram que menos de $15 \%$ dos funcionários apresentam ensino fundamental completo e incompleto. Mais de $65 \%$ apresentam ensino médio completo e incompleto e mais de $20 \%$ dos funcionários já cursaram ou estão cursando o ensino superior

Com relação a treinamentos, consta no relatório social da empresa que em 2008 foram investidos $\mathrm{R} \$ 447.000,00$ em um total de 71.877 horas, ou seja, uma média de 30 horas por funcionário.

\subsection{Discussão dos Resultados do Questionário}

O objetivo das três primeiras afirmações foi verificar se os funcionários reconhecem o posicionamento estratégico da empresa de acordo com a classificação apresentada pelos autores Fleury e Fleury (2001): excelência operacional, inovação em produtos ou em orientação para serviços.

Conforme resultados apresentados na Tabela 1, para a primeira afirmação (AF01), 96,1\% dos respondentes concordaram com a afirmação, o que resultou em um ranking médio (RM) de 4,52 pontos. Para a segunda afirmação (AF02), o resultado obtido foi que $71,9 \%$ de funcionários concordam com a frase e o 
ranking médio $(\mathrm{RM})$ calculado a partir das respostas foi de 3,82 pontos. Nas respostas à terceira frase do questionário (AF03), houve uma negação da afirmação. Os funcionários da empresa estudada não entendem que a empresa tem sua estratégia em orientação para serviços. O ranking médio calculado foi de 2,90 pontos, para uma concordância de apenas 37,9\% dos respondentes. Dessa forma, a partir da análise das respostas das três primeiras afirmações dos questionários, conclui-se que os funcionários entendem que essa empresa tem como estratégias de negócio focar a excelência operacional e a inovação em produtos.

Sendo assim, pode uma empresa ter foco em "excelência operacional" e "inovação de produtos" ao mesmo tempo? Fleury e Fleury (2001) destacam que não é interessante para uma empresa assumir que é, ou deveria ser, igualmente competente em todas as três funções (excelência operacional, inovação em produtos e orientação para clientes). O que se encontra, neste caso, difere ou contraria, em parte, o que expõe a teoria? Aparentemente não. Pelas informações coletadas nas entrevistas e nas análises documentais, verifica-se que as inovações que ocorrem na empresa são incrementais, e que visam o aumento da competitividade da empresa através da excelência em operações. Portanto, esta é uma empresa do tipo commodity, que oferece produtos padronizados $e$, os funcionários da empresa pesquisada reconhecem que a estratégia tem como foco na excelência operacional, o que segundo os autores pesquisados, exige que a empresa explore e desenvolva suas competências essenciais nesta área para obter sucesso.

No referencial teórico apresentado, grande importância foi dada para que os funcionários conheçam a estratégia, os objetivos, a missão, a visão e os valores da empresa. O envolvimento de todos os funcionários em todos os níveis é consenso entre os autores citados, para um bom andamento de um sistema de gestão que busca alinhar as estratégias e competências e obter o sucesso da empresa. Para obter essa informação, foi realizada a análise da quarta afirmação (AF04). O ranking médio obtido foi de 4,29 pontos e, 86,9\% dos participantes concordaram com a afirmação. O que indica que os funcionários conhecem a missão, a visão e os valores da empresa.

Na quinta afirmação (AF05) foi possível testar se, na visão dos funcionários, a missão, a visão e os valores são compatíveis com a realidade da empresa. Dos respondentes aos questionários, 78,4\% dos entrevistados concordaram com a afirmação, e o ranking médio calculado a partir de todas as respostas 
foi de 3,92 pontos. Portanto, de acordo com os funcionários, a missão, a visão e os valores que são conhecidos também são compatíveis com a realidade da empresa.

$\mathrm{Na}$ afirmação de número seis (AF06) do questionário 59,5\% dos pesquisados confirmaram que concordam com a frase, e o resultado do ranking médio das respostas foi de 3,46 pontos. Sendo assim, os funcionários afirmam conhecer as estratégias e objetivos da empresa estudada.

Tabela 1: Respostas dos funcionários ao questionário

\begin{tabular}{|l|c|c|}
\hline \multicolumn{1}{|c|}{ Frases utilizadas no questionário } & $\begin{array}{c}\text { Ranking } \\
\text { Médio }\end{array}$ & $\begin{array}{c}\text { Concordantes } \\
\text { (\%) }\end{array}$ \\
\hline $\begin{array}{l}\text { AF01 - Esta empresa procura oferecer ao mercado produtos que } \\
\text { tem uma boa relação qualidade e preço, ou seja, um produto } \\
\text { bom a um preço competitivo. }\end{array}$ & 4,52 & 96,1 \\
\hline $\begin{array}{l}\text { AF02 - Esta empresa tem como característica oferecer produtos } \\
\text { radicalmente novos. }\end{array}$ & 3,82 & 71,9 \\
\hline $\begin{array}{l}\text { AF03 - Esta empresa é focada no atendimento de clientes } \\
\text { específicos de maneira individual. }\end{array}$ & 2,9 & 37,9 \\
\hline AF04 - Conheço a missão, visão e os valores da empresa. & 4,29 & 86,9 \\
\hline $\begin{array}{l}\text { AF05 - A missão, a visão e os valores são compativeis com a } \\
\text { realidade da empresa. }\end{array}$ & 3,92 & 78,4 \\
\hline $\begin{array}{l}\text { AF06 - Conheço os objetivos e as estratégias de negócio defi- } \\
\text { nidas pela empresa. }\end{array}$ & 3,46 & 59,5 \\
\hline $\begin{array}{l}\text { AF07 - Participei do último planejamento estratégico da empre- } \\
\text { sa onde foram definidos os objetivos e as estratégias de negócio. }\end{array}$ & 2,23 & 21,6 \\
\hline $\begin{array}{l}\text { AF08 - Conheço os indicadores definidos para acompanha- } \\
\text { mento das metas globais da empresa. }\end{array}$ & 3,85 & 73,2 \\
\hline $\begin{array}{l}\text { AF09 - Tenho oportunidade de dar ideias e sugestões que } \\
\text { possam alterar/contribuir a estratégia de negócio da empresa. }\end{array}$ & 3,73 & 68,6 \\
\hline $\begin{array}{l}\text { AF10 - Conheço o programa de gestão por competências que } \\
\text { foi implantado na empresa. }\end{array}$ & 4,24 & 86,2 \\
\hline $\begin{array}{l}\text { AF11 - O programa de gestão por competências é importante } \\
\text { para a implementação da estratégia de negócio da empresa. }\end{array}$ & 4,41 & 88,9 \\
\hline $\begin{array}{l}\text { AF12 - As competências organizacionais definidas (citadas aci- } \\
\text { ma) estão alinhadas com a estratégia de negócio e os objetivos } \\
\text { da empresa. }\end{array}$ & 4,13 & 83,7 \\
\hline $\begin{array}{l}\text { AF13 - A empresa investe no desenvolvimento (treinamento) } \\
\text { dos funcionários nestas competências organizacionais. }\end{array}$ & 4,03 & 81,7 \\
\hline $\begin{array}{l}\text { AF14 - As competências organizacionais são comunicadas e } \\
\text { divulgadas para todos os funcionários. }\end{array}$ & 4,12 & 81,7 \\
\hline
\end{tabular}




\begin{tabular}{|c|c|c|}
\hline Frases utilizadas no questionário & $\begin{array}{l}\text { Ranking } \\
\text { Médio }\end{array}$ & $\begin{array}{c}\text { Concordantes } \\
(\%)\end{array}$ \\
\hline $\begin{array}{l}\text { AF15 - Estas competências organizacionais estão bem desen- } \\
\text { volvidas em seu superior. }\end{array}$ & 3,85 & 75,2 \\
\hline $\begin{array}{l}\text { AF16 - Sou avaliado ou recebo retorno do meu superior sobre } \\
\text { meu desempenho nestas competências. }\end{array}$ & 3,44 & 60 \\
\hline $\begin{array}{l}\text { AF17 - Essas competências organizacionais são importantes } \\
\text { para o resultado do meu trabalho. }\end{array}$ & 4,61 & 94,4 \\
\hline $\begin{array}{l}\text { AF18 - Considero que tenho essas competências organizacio- } \\
\text { nais altamente desenvolvidas. }\end{array}$ & 3,81 & 77,3 \\
\hline $\begin{array}{l}\text { AF19 - Os funcionários desta empresa têm estas competências } \\
\text { organizacionais altamente desenvolvidas. }\end{array}$ & 3,0 & 47,1 \\
\hline \multicolumn{3}{|l|}{$\begin{array}{l}\text { AF20 - Ocorrem situações durante execução de minhas ativi- } \\
\text { dades onde }\end{array}$} \\
\hline emprego estas competências organizacionais. & 4,26 & 87,8 \\
\hline $\begin{array}{l}\text { AF21 - A empresa desenvolve um ambiente organizacional } \\
\text { que propicia a tomada de decisão por empregados em todos } \\
\text { os níveis hierárquicos. }\end{array}$ & 3,18 & 53 \\
\hline $\begin{array}{l}\text { AF22 - O processo decisório na empresa pode ser caracterizado } \\
\text { como demorado e burocrático. }\end{array}$ & 3,5 & 62,3 \\
\hline $\begin{array}{l}\text { AF23 - A empresa possui uma cultura que enfatiza a apren- } \\
\text { dizagem através de programas de Educação e Treinamento. }\end{array}$ & 3,85 & 75,2 \\
\hline $\begin{array}{l}\text { AF24 - A empresa incentiva e recompensa a postura criativa e } \\
\text { empreendedora dos profissionais. }\end{array}$ & 3,53 & 64,8 \\
\hline $\begin{array}{l}\text { AF25 - Os funcionários não têm capacidade e não estão pre- } \\
\text { parados para realizar trabalhos mais complexos e elaborados } \\
\text { do que aqueles que fazem atualmente. }\end{array}$ & 2,26 & 22,9 \\
\hline $\begin{array}{l}\text { AF26 - Os empregados estão preocupados apenas com suas } \\
\text { atividades e não com os resultados globais da empresa. }\end{array}$ & 2,62 & 34,6 \\
\hline
\end{tabular}

Fonte: Elaborado pelo autor deste artigo

Para verificar a participação dos funcionários de todos os níveis da organização no planejamento estratégico foi utilizada a afirmação número sete (AF 07). Dos respondentes, apenas $21,6 \%$ afirmaram ter participado do último planejamento estratégico da empresa, e o ranking médio que resultou das respostas foi de 2,23 pontos. Sendo assim, de acordo com os dados apresentados na Tabela 1, não se pode afirmar que os funcionários de todos os níveis e cargos da empresa estudada participaram da elaboração do planejamento estratégico. A oitava afirmação (AF08) utilizada no questionário foi: "Conheço os indicadores definidos para acompanhamento das metas globais da empresa". 
O ranking médio das respostas foi de 3,85 pontos, e 73,2\% dos respondentes concordaram com a frase. Dessa forma, diante das respostas dos entrevistados considera-se verdadeira a afirmação. Conclui-se que as ferramentas utilizadas pela empresa para controle da estratégia, dentre elas como foi citado, o BSC, estão atingindo a organização como um todo.

Nas respostas à nona afirmação (AF09) do questionário, os funcionários concordaram que eles tem oportunidade de dar ideias e sugestões que possam alterar/contribuir a estratégia de negócio da empresa. O ranking médio das respostas foi de 3,73 pontos, e 68,6\% assinalaram as opções: "concordo parcialmente" ou "concordo totalmente". Com as informações coletadas nas entrevistas e nas análises documentais, pode-se sugerir que um ponto que contribui para essa afirmação é que os funcionários veem no programa de participação utilizado pela empresa intitulado como "Grupos de Estudos e Sugestões" (GES), uma ferramenta pela qual eles podem fazer com que suas ideias cheguem até o mais alto escalão. Se ela não for implementada, eles terão no mínimo uma resposta que justifique a sua não aplicação. Conforme já apresentado, para Fleury e Fleury (2001), a adoção de estratégias para a participação dos empregados, como os tradicionais programas de sugestão, são utilizados nas empresas consideradas modelo de alinhamento entre estratégia e competências. Sendo assim, aqui tem-se um ponto importante de confirmação do referencial teórico.

Diante do que foi exposto pode-se dizer, resumidamente, que os funcionários da empresa estudada reconhecem que a sua estratégia é pautada em excelência operacional e inovação em produtos. Outro ponto importante é que os funcionários conhecem também a missão, a visão e os valores da empresa e que eles estão de acordo com o que vem sendo praticado. O entendimento da estratégia e objetivos pelo maior número de pessoas possível, em todos os níveis, não apenas pela alta gerência, é o que é recomendado pela literatura para o sucesso da empresa no alinhamento entre estratégia e competências. Mesmo apontando na pesquisa que os funcionários em geral não participaram da elaboração do planejamento estratégico, ficou claro que os funcionários de todos os níveis e áreas entendem que podem dar ideias e sugestões que possam alterar ou contribuir com a estratégia de negócio da empresa. Isso corrobora com a teoria apresentada, em que a estratégia deve ser uma tarefa de todos e que deve ser um processo contínuo (KAPLAN; NORTON, 2000). Mesmo que os funcionários não participem do planejamento com suas estratégias deliberadas, surgem importantes indícios da administração estratégica dando espaço para as 
estratégias emergentes que dependem do desenvolvimento das competências individuais e do aprendizado para que todos possam participar da formulação das estratégias, conforme apontado por Costa (2003).

Algumas afirmações foram utilizadas para obter informações sobre o programa de gestão por competências que foi implantado na empresa estudada. A primeira delas foi a afirmação dez (AF 10). O ranking médio calculado a partir das respostas encontradas foi de 4,24 pontos para $86,2 \%$ dos funcionários que concordaram que conhecem o programa de gestão por competências. Para Brandão e Guimarães (2001), quando a gestão de competências envolve os diversos níveis da organização desde o corporativo até o individual, passando pelo divisional e grupal, forma-se um processo circular, o que é importante para o sucesso do programa de gestão e para o alinhamento com a estratégia.

Para verificar a importância que os funcionários dão ao programa de gestão por competências, eles responderam à afirmação 11 (AF11). O ranking médio obtido para as respostas foi de 4,41 pontos com $88,9 \%$ de concordância dos funcionários, um valor muito alto, conforme ilustra a Tabela 1. Assim, como resposta deste grupo estudado tem-se que os funcionários acham que o programa de gestão por competências é importante para a implementação da estratégia de negócio da empresa. De acordo com o apresentado referencial teórico, para que se obtenha o alinhamento entre estratégia e competências é muito importante verificar como o processo é entendido e, como funciona a aceitação das pessoas, principalmente os gestores, que são considerados agentes da mudança (COSTA, 2003).

A resposta à afirmação 12 (AF12) foi a de que os funcionários concordam que as competências organizacionais definidas estão alinhadas com a estratégia e os objetivos da empresa. O ranking médio obtido para essa afirmação foi de 4,13 pontos com $83,7 \%$ de concordância dos funcionários. Esse é com certeza um ponto muito importante e confirma o que foi apresentado por Brandão $e$ Guimarães (2001). Eles afirmam que a gestão de competências tem que estar em perfeita sintonia com a estratégia (missão, visão de futuro e objetivos).

Por meio da afirmação de número 13 (AF13) foi possível verificar que a empresa investe no treinamento e desenvolvimento dos funcionários nas competências organizacionais definidas como importantes para a empresa alcançar seus objetivos estratégicos. Isso é confirmado nos resultados dos questionários aplicados, pois $81,7 \%$ assinalaram que concordam com a afirmação e o ranking médio obtido foi de 4,03 pontos. 
De acordo com a teoria apresentada, das competências organizacionais trabalhadas pela empresa estudada, as que estão relacionadas diretamente com as estratégias de excelência operacional são as chamadas competências essenciais. E no modelo apresentado para integrar as estratégias às competências, o desenvolvimento das competências essenciais é considerado a peça-chave das práticas de gestão, pois são elas que diferenciam e que garantem uma vantagem competitiva sustentável perante as demais organizações (FLEURY; FLEURY, 2001). Essa competitividade vai depender ao longo do tempo da administração do processo de aprendizagem organizacional, que acontece através do treinamento contínuo dos funcionários. Sendo assim, a empresa, segundo as repostas obtidas, segue o que a teoria determina e está investindo no treinamento e desenvolvimento de seus funcionários nas competências organizacionais.

Para identificar a eficiência da comunicação interna das competências, foi utilizada a afirmação 14 (AF14): "As competências organizacionais são comunicadas e divulgadas para todos os funcionários". O ranking médio obtido das respostas foi de 4,12 pontos e $81,7 \%$ dos respondentes assinalaram "concordo parcialmente" ou "concordo totalmente". Sendo assim, diante desses resultados que estão apresentados na Tabela 1, pode-se concluir que os respondentes concordam que as competências organizacionais são comunicadas e divulgadas para todos os funcionários. Uma comunicação clara mostrando quais são os objetivos estratégicos, quais são as competências necessárias para desenvolvê-lo, quais serão os ganhos para a organização e seus impactos na vida funcional, é condição essencial para que os funcionários se tornem envolvidos e comprometidos.

Como a empresa estudada não possuía um sistema de avaliação de desempenho implantado, foram utilizadas algumas afirmações para verificar na visão dos entrevistados como está o desenvolvimento das competências nos funcionários. Para analisar o desenvolvimento das competências organizacionais nos cargos de chefia foi utilizada a afirmação 15 (AF15). Para essa afirmação, o ranking médio de todas as respostas ficou em 3,85 pontos com $75,2 \%$ dos respondentes concordando com a afirmação. Como já foi dito, os executivos são verdadeiros agentes da mudança e, portanto, os resultados das avaliações das competências dos gestores são uma fonte importante para a verificação do alinhamento entre estratégias e competências (COSTA, 2003). Assim, na visão dos subordinados que participaram da pesquisa, os resultados apontam que 
os gestores têm as competências organizacionais desenvolvidas. O que a teoria sugere como importante para o alinhamento entre estratégia e competências.

Com o objetivo de verificar se os gestores estão utilizando o sistema de gestão por competências para análise e desenvolvimento de seus subordinados foi utilizada a afirmação 16 (AF16). Mesmo não existindo uma periodicidade formal para realizar-se a avaliação de desempenho por competências, segundo informações obtidas nas entrevistas, a empresa estimula sua utilização. Os pesquisados, em sua maioria (60\%), concordaram que são avaliados ou recebem retorno dos seus superiores sobre os seus desempenhos nas competências organizacionais. Com a análise das respostas obteve-se um ranking médio de 3,44 pontos. Dada a importância já citada dos gestores para o alinhamento entre estratégia e competências, a percepção destes em relação ao sistema de gestão de pessoas por competências é muito importante. O fato de estarem utilizando essa ferramenta de gestão indica que a empresa está seguindo o que é considerado como importante pela teoria e entende que a gestão por competências faz parte da estratégica.

Na afirmação 17 (AF17) foi possível analisar mais uma vez a importância dada pelos funcionários à gestão por competências. Dos participantes, 94,4\% concordaram com a frase, e o ranking médio de todas as respostas foi de 4,61 pontos, como mostra a Tabela 1 . Assim, esses resultados confirmam que os funcionários estudados de todos os níveis e áreas, acham que as competências organizacionais definidas pela empresa para serem desenvolvidas são importantes para uma boa execução de suas atividades diárias.

A afirmação 20 (AF20) também tem objetivo semelhante ao objetivo da anterior: "Ocorrem situações durante execução de minhas atividades onde emprego estas competências organizacionais". Para essa afirmação o ranking médio obtido foi de 4,26 com uma concordância de $87,8 \%$ dos funcionários pesquisados.

Dessa forma, a partir das respostas às afirmações AF17 e AF20 pode-se inferir que os funcionários estão trabalhando em busca da implementação dos objetivos e estratégias definidas, já que além de existir um consenso entre todos sobre a importância das competências organizacionais para execução de suas atividades, elas também estão sendo empregadas e praticadas no dia a dia. Consequentemente, estas competências entram em um processo de desenvolvimento nos funcionários das diversas áreas e níveis. No momento em que os funcionários reconhecem a importância das competências ocorre um empenho 
elevado de todos para o desenvolvimento das competências necessárias ao atendimento do plano estratégico.

Assim como na afirmação 15 (AF15), nas afirmações 18 (AF18) e 19 (AF19) foi medido o desenvolvimento das competências individuais dos funcionários. A afirmação 18 utilizada no questionário era: "Considero que tenho essas competências organizacionais altamente desenvolvidas". O ranking médio obtido foi de 3,81 pontos, e 77,3\% dos respondentes concordaram com a afirmação. Esse resultado indica que na autoavaliaçao realizada pelos funcionários, eles consideram ter as competências desenvolvidas. Comparando-se com o que diz a teoria, esta informação torna-se importante, pois segundo Costa (2003), pode-se deduzir que há uma forte relação entre as competências e as estratégias se, o resultado final apontar que a maioria dos empregados atende as competências requeridas.

Para a afirmação 19 (AF19) foi utilizada a frase: "Os funcionários desta empresa têm estas competências organizacionais altamente desenvolvidas". O ranking médio obtido a partir das respostas ao questionário foi de 3,0 pontos. Segundo a metodologia utilizada neste trabalho, para um valor exatamente 3, deverá ser considerado como "indiferente" ou "sem opinião", sendo o "ponto neutro", equivalente aos casos em que os respondentes deixaram em branco. Apareceu aqui uma dificuldade clara do grupo estudado em avaliar o desenvolvimento das competências dos demais funcionários. Pode-se associar isso ao fato do grupo estudado ser uma representação do quadro da empresa, onde a maioria é do nível operacional $(70 \%)$. Nesse nível, as pessoas podem sentir dificuldades em avaliar os funcionários da empresa como um todo, e provavelmente preferiram não opinar.

Com o objetivo de verificar se o ambiente da empresa era favorável ao alinhamento entre as competências organizacionais e a estratégia, foram definidas algumas afirmações no questionário. Para a afirmação 21 (AF21), o ranking médio das respostas foi de 3,18 pontos, com concordância de $53 \%$ dos respondentes. Esses resultados encontrados sugerem que os funcionários concordam que a empresa estimula a tomada de decisão em todos os níveis. Mas estes valores estão longe da unanimidade, pouco mais da metade dos respondentes concordaram com a afirmação. Apesar de positiva a resposta, este é um ponto importante a ser observado. A teoria apresentada por Costa (2003) diz que a empresa deve evitar arquétipos organizacionais centralizados e burocráticos voltados para somente uma parte da organização. 
Ainda sobre o ambiente organizacional, no questionário foi apresentada a afirmação 22 (AF 22) cujo processo decisório na empresa foi analisado. Foi obtido um ranking médio de 3,50 pontos, onde $62,3 \%$ dos respondentes ao questionário caracterizaram o processo decisório da empresa como demorado e burocrático (Tabela 1). Esse comportamento corrobora com os princípios da administração estratégica apontados anteriormente.

Para analisar treinamento e desenvolvimento foi utilizada a afirmação AF23. Na Tabela 1 pode-se visualizar que 75,2\% dos respondes concordam que a empresa enfatiza a aprendizagem através de programas de educação $e$ treinamento. O ranking médio calculado para as respostas foi de 3,85 pontos. $O$ resultado geral mostrou que a empresa preocupa-se com o desenvolvimento de seus funcionários, o que, conforme apresentaou-se no referencial teórico, é um fator condicionante para as pessoas se constituírem num fator de vantagem competitiva em uma organização, e também para demonstrar o alinhamento das competências com a estratégia. Segundo Costa (2003), o nexo entre estratégias empresariais e as competências individuais é a aprendizagem organizacional $e$ individual. A aprendizagem individual se dá por meio de educação e treinamento, ou seja, esse é o meio de se desenvolver as competências. Por meio do treinamento contínuo dos funcionários, novas habilidades serão desenvolvidas e melhoradas. A empresa que foca suas ações na aprendizagem das pessoas e por consequência da aprendizagem organizacional, está direcionando suas ações para as competências individuais e essenciais. E uma empresa, tem que explorar e desenvolver suas competências essenciais de maneira consistente com as estratégias empresariais definidas.

Nas respostas para a $24^{\circ}$ afirmação (AF 24) ficou claro que os funcionários concordam que a empresa incentiva e recompensa a postura criativa e empreendedora dos profissionais. Para essa frase, o ranking médio das respostas foi de 3,53 pontos, com $64,8 \%$ dos funcionários concordando com a afirmação. Segundo as informações coletadas nos processos de entrevista, a empresa em seu programa de "Grupo de Estudos e Sugestões" (GES) tem uma premiação para os membros dos grupos que se destacam mensalmente e anualmente. Com certeza, a realização desse programa é visto pelos funcionários como um caminho para sua participação na gestão da empresa e também para o seu reconhecimento. Dessa forma, a empresa tem uma ferramenta participativa muito importante que vai de encontro aos princípios da administração estratégica apresentados no referencial teórico, que defende o envolvimento de todos e não de somente uma parte da organização. 
Para a $25^{\circ}$ frase do questionário foi utilizada uma negação (AF 25): "Os funcionários não têm capacidade e não estão preparados para realizar trabalhos mais complexos e elaborados do que aqueles que fazem atualmente". Os funcionários que responderam ao questionário não concordam com a frase, pois o ranking médio obtido foi de 2,26 pontos, e apenas $22,9 \%$ assinalaram "concordo parcialmente" ou "concordo totalmente". Pode-se afirmar que os respondentes a pesquisa acham que os funcionários como um todo podem ser envolvidos para realizar atividades mais complexas e elaboradas. Mesmo que já estejam sendo envolvidos em alguma parte do processo decisório, de gestão e estratégico da empresa, essa resposta nos leva a supor que este envolvimento pode ser ainda mais frequente e profundo do que vem sendo feito atualmente. Essa é uma condição importante e que deve ser avaliada pela empresa estudada. $\mathrm{O}$ fato de a equipe estar pronta para assumir um maior envolvimento é, com certeza, um fator desejável para qualquer empresa que queira diferenciação no mercado. Fala-se de uma equipe que demonstra ter potencial para desenvolver ainda mais uma cultura interna de atenção aos aspectos estratégicos e competitivos, e favorecer o desenvolvimento de competências e comportamentos organizacionais, agregando com as experiências e conhecimentos para o aperfeiçoamento dos processos e fortalecimento do diferencial competitivo da organização.

Além de verificar a capacidade das pessoas em assumir mais responsabilidades, é importante saber se essas pessoas têm interesse em envolver-se. Isso certamente está relacionado com o ambiente desenvolvido dentro da organização. Para isso foi utilizada a frase AF26: "Os empregados estão preocupados apenas com suas atividades e não com os resultados globais da empresa". O resultado mostrou uma discordância dos respondentes. Conforme ilustra a Tabela 1, o ranking médio obtido para as respostas foi de 2,62 pontos, $e$ apenas $34,6 \%$ concordaram com a frase. Portanto, pode-se considerar que os funcionários estão preocupados com os resultados globais da empresa estudada e, se está diante de um resultado que demonstra estar de acordo com o referencial teórico estudado. Como se viu, o conceito de competências está ligado à ação e à entrega. Não adianta o funcionário ter conhecimentos e habilidades se ele não tiver uma atitude de entrega, de realmente querer fazer.

Resumidamente, a respeito da gestão por competências implantada na empresa estudada, pode-se dizer que por meio de um processo de comunicação bem implementado obteve-se um quadro de funcionários que conhece o programa de gestão por competências e concorda que ele é importante 
para a implementação da estratégia da empresa. Também foi verificado que a empresa investe no treinamento e desenvolvimento destas competências $e$ que o resultado deste treinamento é positivo, já que os empregados afirmam ter suas competências individuais desenvolvidas e da mesma forma vêem isto em seus superiores.

\section{Conclusões}

Verificou-se que a empresa que busca um ambiente propício ao alinhamento deve desde a seleção, obter funcionários com elevado nível de escolaridade e com potencial de crescimento e com pensamento estratégico. No caso em estudo, a empresa optou por ter seu próprio colégio para formar sua mão de obra qualificada, além de utilizar bolsas e demais incentivos para promover o desenvolvimento. Assim, é importante que a empresa seja focada no desenvolvimento, crescimento e aprendizagem, tendo um corpo de bom nível educacional, pois os conhecimentos formais são necessários para a construção de competências.

Além disso, a empresa deve estimular a tomada de decisão em todos os níveis hierárquicos, de modo a desenvolver a visão estratégica dos funcionários. Deve assumir uma postura de recompensa e valorização dos comportamentos criativos e empreendedores. Os grupos de estudos e sugestões associados às premiações surgiram neste caso estudado como uma ferramenta para alcançar este objetivo. Mas, somente isso parece não ser suficiente, pois os funcionários apontaram que poderiam ser envolvidos para realizar atividades mais complexas e elaboradas do que vem fazendo atualmente. Considerou-se também que o processo decisório na empresa pode ser caracterizado como demorado $e$ burocrático. Apesar dos resultados encontrados sugerirem que os funcionários em geral, concordam que a empresa estimula a tomada de decisão em todos os níveis, os valores ficaram longe da unanimidade. Na verdade, segundo a literatura, tudo deve estar ligado a uma gestão participativa na qual todos se sentem responsáveis pela estratégia e pelo resultado global da empresa. $\mathrm{Na}$ prática, isso é muito difícil de ser alcançado e, no caso em estudo, as práticas atuais precisam ser melhoradas.

A utilização de um processo de avaliação e remuneração por competências é muito importante para consolidar esse processo. No caso estudado, a 
empresa utiliza a avaliação de desempenho de forma tímida, o que prejudica a utilização dos resultados das avaliações para realizar os ajustes na gestão de pessoas e buscar o alinhamento com a estratégia. Mesmo utilizando de algumas formas de remuneração variável, o caso em estudo não permitiu verificar os resultados apresentados pela literatura, por não utilizar a remuneração por competências em seu sistema de gestão.

Uma boa comunicação é necessária para difundir missão, visão e valores, ou seja, onde seus dirigentes querem chegar. Para isso, devem ser criados canais e condições para que os objetivos e as estratégias e o caminho a ser percorrido (que passa pelas competências organizacionais a serem desenvolvidas), sejam discutidos e entendidos pelo maior número possível de pessoas na empresa, de todas as áreas e níveis. No caso estudado, a empresa criou uma comissão para cuidar da comunicação interna. Os resultados da pesquisa indicam que da maneira como está sendo realizado, o processo de comunicação tem atingido seus objetivos.

Também é importante que as competências organizacionais escolhidas para serem desenvolvidas sejam validadas com pessoas de vários níveis e áreas da organização. Na empresa estudada, as competências organizacionais foram validadas por meio de um trabalho realizado com a equipe de gerentes, coordenadores e supervisores de todas as áreas. Pode-se dizer que essa atividade foi realizada com sucesso, pois os resultados apontam que os funcionários reconheceram que as competências organizacionais que foram definidas para ser trabalhadas, estão alinhadas com a estratégia e os objetivos da empresa; $e$ também são importantes para a realização de suas atividades.

O planejamento estratégico deve ter a participação de um grande número de pessoas de todos os níveis e áreas, inclusive de recursos humanos. No caso em estudo, apesar da empresa afirmar que foram utilizadas metodologias que envolviam representantes de todas as áreas e níveis, o resultado da pesquisa apontou que os funcionários não sentiram-se envolvidos no planejamento estratégico. Portanto, na prática é extremamente complicado conseguir o que sinaliza a teoria. Mas por outro lado, o fato dos funcionários como um todo não poderem participar da elaboração do plano estratégico, não significa que as pessoas não possam ser envolvidas na gestão estratégica da empresa. Conforme já citado, a empresa conseguiu através de um programa de estudos e sugestões bem elaborado, que os funcionários tenham oportunidade de dar ideias e sugestões que possam contribuir com a estratégia de negócio da em- 
presa. Assim, é possível traços importantes da administração estratégica em que os funcionários sentem-se envolvidos e com estímulo a influenciar na gestão estratégica da empresa.

Constata-se que a visão dos funcionários sobre o programa de gestão por competências influencia no alinhamento entre a estratégia $e$ as competências organizacionais. É fundamental que em todos os níveis e áreas da empresa os funcionários conheçam a missão, a visão, os valores, as competências e as estratégias definidas. Além disso, deve existir consenso entre todos que estes itens são adequados à realidade e objetivos da empresa. Ou seja, os funcionários de todos os níveis e áreas devem acreditar que estes itens são importantes para uma boa execução de suas atividades diárias. Para isso, torna-se importante que a empresa ao formular suas estratégias considere seus recursos e capacidades internas e defina quais são as competências organizacionais que devem ser desenvolvidas para alcançar seus objetivos estratégicos. Esse é um passo importante para que o alinhamento ocorra.

O envolvimento dos gestores no programa de gestão por competências também é um caminho a ser seguido, pois eles são agentes da mudança. A sensibilização destes, passa pelo processo de envolvimento na elaboração e definição dos programas, aliado, a um bom processo de comunicação. Surge a importância dos gestores no processo de alinhamento, seja pela comunicação ou pelo envolvimento próprio e dos seus subordinados.

Para o desenvolvimento das competências individuais a empresa deve investir no treinamento e desenvolvimento dos funcionários nas competências organizacionais definidas como importantes para a empresa alcançar seus objetivos estratégicos. O desenvolvimento das competências ligadas às estratégias denominadas competências essenciais, é o ponto de ligação, o que representa de forma mais clara o alinhamento.

Portanto, uma empresa que busca alinhar a estratégia e as competências organizacionais deve analisar o seu ambiente organizacional, o seu processo de comunicação (principalmente internamente) e deve-se valer de ferramentas que promovam a gestão participativa, preocupando-se em envolver o maior número de funcionários de todos os níveis e áreas, desde o planejamento até a execução do seu planejamento estratégico e do programa de gestão por competências. Para que seus funcionários estejam preparados para o envolvimento, a empresa deve focar a seleção, o treinamento e desenvolvimento de suas competências individuais, eliminando os gaps existentes com as competências organizacionais consideradas essenciais. 


\section{The Alignment Between Strategies and Organizational Competences: the case for a national company leader in ceramic tile}

\section{Abstract}

The main objective of this study is to present and discuss the alignment between business strategies and organizational competences. From the theoretical and the experience of the company studied, this paper presents what are the characteristics of the company and how it should be an organizational environment to facilitate this alignment. As a company should proceed and what tools can be used to enable the participation of officials from all levels and areas, from planning to execution of its strategic plan and program management competences. It also shows the importance of developing competences related to strategy, called core competences. This organizational development occurs with the training of employees and the growth of their respective individual competences, promoting links between business strategies and organizational competences through individual and organizational learning.

Key words: Strategic Planning. Strategic Administration. Organizational Competences. People Management. Core competences. Individuals Competences.

\section{Referências}

ANDREWS, K. R. The concept of corporate strategy. Homewood, IL: Irwin, 1971.

BRANDÃO, H. P.; GUIMARÃES, T. A. Gestão de competências e gestão de desempenho: tecnologias distintas ou instrumentos de um mesmo construto? Revista de Administração de Empresas da EAESP/FGV, São Paulo, v. 41, n. 1, p. 8-15, jan./mar. 2001.

CERTO, S. C.; PETER, J. P. Administração estratégica: planejamento e implantação estratégica.São Paulo: Pearson Education do Brasil, 1993. 
COSTA, M. A. S. Administração estratégica e gestão de pessoas por competências: o caso Policarbonato. 2003. 200f. Dissertação (Mestrado Profissional) Universidade Federal da Bahia, Escola de Administração, Salvador, 2003.

CURRIE, G. DARBY, R. Competence-based management development: rhetoric and reality. Journal of European Industrial Training, v. 19, n. 5, p. 11-18, 1995.

DUTRA, J. S. Gestão de pessoas com base em competências. In: DUTRA, J.S. et al. (Org.). Gestão por competências: um modelo avançado para o gerenciamento de pessoas. São Paulo: Gente, 2001, p. 25-43.

FERREIRA, A. A.; REIS, A. C. F; PEREIRA, M. I. Gestão empresarial: de Taylor aos nossos dias: evolução e tendência da moderna administração de empresas. São Paulo: Pioneira, 1997.

FISHER, A. L. A construção do modelo competitivo de gestão de pessoas no Brasil: um estudo sobre as empresas consideradas exemplares. Tese (Doutorado) - Faculdade de Economia, Administração e Contabilidade, Universidade de São Paulo, São Paulo, 1998.

FISCHMANN, A. A. Implementação de estratégias: identificação e análise de problemas. Tese (Livre Docência). São Paulo, FEA-USP,1987.

FLEURY, A. C. C.; FLEURY, M. T. L. Estratégias empresariais e formação de competências: um quebra-cabeça caleidoscópio da indústria brasileira. São Paulo: Atlas, 2001.

. Alinhando estratégia e competências. Revista de Administração de Empresas, São Paulo, v. 44, n. 1, p. 44-57, 2004.

KAPLAN. R. S. NORTON, D. P. Organização orientada para a estratégia. Rio de Janeiro: Campus, 2000.

MALHOTRA, N. Pesquisa de marketing: uma orientação aplicada. Porto Alegre: Bookman, 2001.

MILLS, J. et al. Competing through competences. Cambridge: Cambridge University Press, 2002. 
MINTZBERG, H. A criação arsenal da estratégia. In: MONTGOMERY, C. A.; PORTER, M. E. (Org.) Estratégia: a busca da vantagem competitiva. Rio de janeiro: Campos, 1998. (Cap. 4).

MINTZBERG, H; QUINN, J. B. O processo da estratégia. 3. ed. Porto Alegre: Bookman, 2001.

NISEMBAUM, H. A competência essencial. São Paulo: Infinito, 2000.

PARRY, S. B. The quest for competencies. Training, Minneapolis, Minn, v. 33, n. 7, p. 48-54, July, 1996.

PRAHALAD, C. K.; HAMEL, G. The core competence of the corporation. Harvard Business Review, v. 68, n. 3, p. 79-91, 1990.

SERRALHEIRO, W. A. O. O processo de adaptação estratégica das empresas Eliane sob a ótica da teoria institucional e da visão baseada em recursos (RBV). 2004. 154 f. Dissertação. (Mestrado) - Programa de Pós-graduação em Engenharia da Produção. Universidade Federal de Santa Catarina, Florianópolis, 2004.

ZARIFIAN, P. Objetivo competência: por uma nova lógica. São Paulo: Atlas, 2001. 